\title{
Cautious Optimism
}

\author{
A report of Council Meeting held in \\ Athens on 27/28 March 1992
}

Council this year was hosted with great generosity by the Hellenic Physical Society, whose immediate past-President, Professor K.C. Makropoulos, opened the two-day meeting by stressing the importance to his country of student mobility and professional qualifications. But expanding fields of research and education, notably the environment for which his city's reputation is not too sparkling, must not be overlooked. A record number participated since the Presidents of national societies had been invited to discuss an EPS restructuring document (see page 75). They included M.F. Thomaz, President of the Portuguese Physical Society and his country's Secretary of State for Science and Technology.

In his introductory address, M. Jacob, the EPS President, referred to his report for 1991 [see EN 23 (1992) 34], stressed the positive response to the restructuring document, and thanked the Institute of Physics for help in analysing its financial implications. Turning to today's concerns, societies having difficulty paying fees should not be written off. He asked them to discuss their problems with N. Kroo, the Vice-President, and appealed for help at the society level from better-off societies. EPS projects must continue to be "cut to our size" as was the case for the East-West Task Force initiatives and a library aid scheme he proposed for Russia, whose physicists should be helped by EPS.

H. Ryde, the Secretary, thanked G. Thomas, the Executive Secretary, and his staff for the smooth running of a Secretariat split between Geneva and Budapest, noting that the division of activities still needs to be looked at when G. Thomas is again based full-time in Geneva next year. He recommended acceptance of membership applications by four new or reconstituted national societies (Albania, Croatia, Estonia and Lithuania), reiterating that the Society was prepared to make arrangements for the payment of fees in case of difficulties. With regard to the Divisions: Optics had been dissolved and an enlarged Quantum Electronics had changed its name to Quantum Electronics and Optics. Professional and training activities at the European level were of growing importance, particularly qualifications and student mobility where EPS could make valuable contributions.

The report of the Treasurer, $\mathrm{Ph}$. Choquard, has also been summarised in Europhysics News [EN 23 (1992) 37]. The 1992 budget proposed by the Executive Committee, and accepted by Council, planned for a reduction of the accumulated deficit to $23 \mathrm{kSFR}$ by the end of 1992. He envisaged an evolutionary budget for 1993 with zero deficit at the end of the year, the Executive Secretary based in Geneva from January 1993, and no liabilities. The Society would be considering

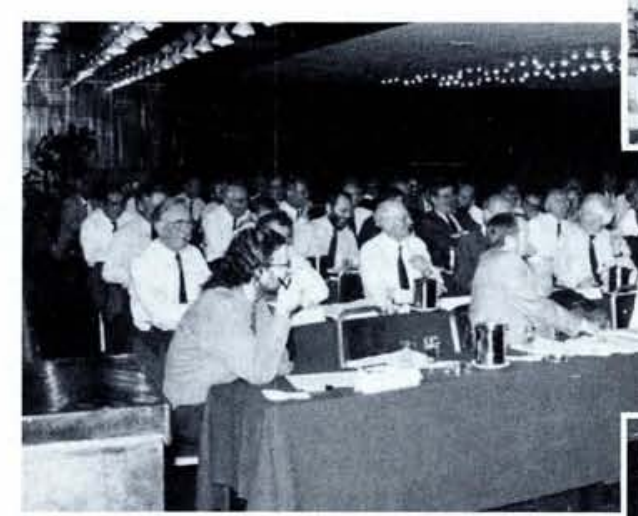

EPS Council Meeting in Athens. Top - the view across Athens. Bottom: Professor G. Karras, President of the Hellenic Physical Society, welcoming delegates at a dinner hosted by the Society.

its future priorities and the profile of expenditures pending a restructuring. Costs would increase in line with inflation but some funds would be made available for stimulating Divisional initiatives, tasks related to restructuring, next year's EPS-9 General Conference, and east-west activities. Professor Choquard acknowledged contributions from the French Commissariat à I'Energie Atomique to meet the expenses of E. Brézin in his capacity as Chairman of the EPS-9 Programme Committee and to help cover the cost of Council next year in Nice. In reply to questions, Professor Choquard reaffirmed that realistic estimates of future income from national societies in central and eastern Europe (C\&EE) had been incorporated in the 1992 budget and in the 1993 projection, and that restructuring in 1993 was not contemplated. An increase in the unit fee from 13.30 SFR to 15.00 SFR to adjust for inflation independent of restructuring may be proposed to Council in 1993, but its eventual impact would probably be diminished by a continuing weakness in the Swiss franc.

\section{A. Sileika who represented the Lithuanian} Physical Society.

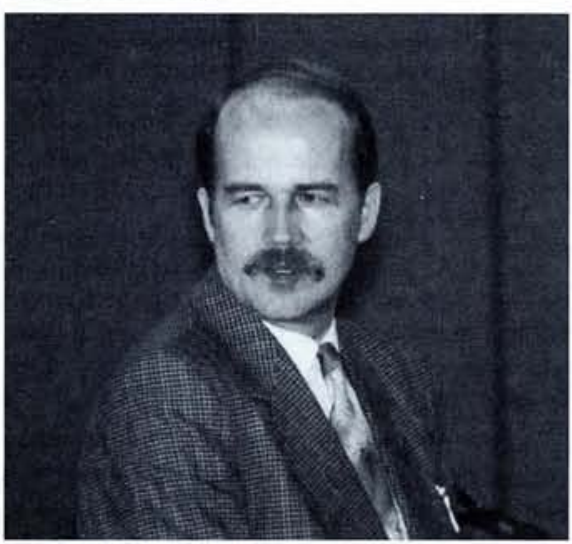

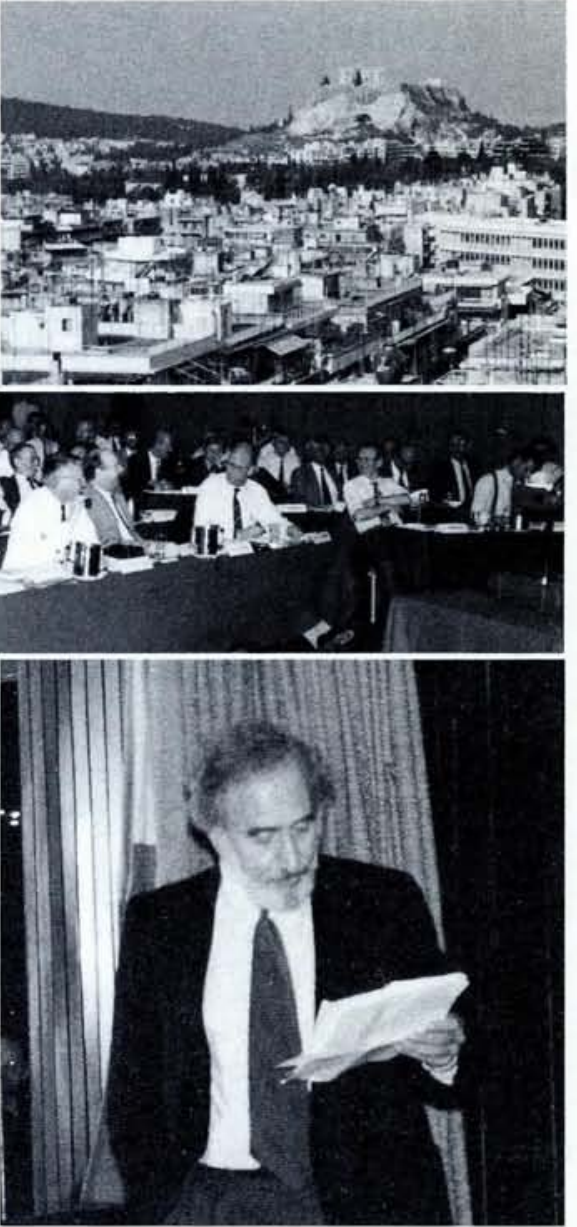

A feature of $1991 / 2$ was a healthy increase in Associate Member contributions largely owing to noteworthy success in attracting physics institutes by a "proximity effect" in Switzerland and more recently in Scandinavia. He urged extension of the campaign to other countries, as EPS could provide institutes with valuable support in return for relatively stable financial contributions, and the continuation of the coordination by P.G. Boswell (Editor, Europhysics News) of other fund-raising efforts.

\section{New Members}

R.A. Ricci (President, Italian Physical Society) strongly supported acceptance of the four new national societies as members, especially the Croatian Physical Society (140 members including teachers ) which was founded in 1985 and has strong links to his society. M. Jacob explained that the present national society representation for Yugoslavia included the Institute "Ruder Boskovic" in Zagreb but the Institute and the Croatian society had agreed to share representation during 1992. The Albanian Physical Society was founded in 1991 with 200 members. J. Kikas, the Chairman of the Estonian Physical Society said his Society had been founded in 1989 and now has some $\mathbf{2 0 0}$ members. The Lithuanian Physical Society, also with about 200 members and represented at the meeting by $A$. Sileika, had been founded in 1963 but its constitution had been revised many times up until 1990. Council warmly approved membership of the four new member socie- 
ties and the President noted that several more applications should be expected, including one from Byelorussia.

All the candidates (see page 79) proposed for the next Executive Committee were elected. Of the current committee members, $\mathrm{H}$. Ryde had completed his term of resigned owing to changes in commitments. The President thanked all for their support and remarked upon Professor Folberth's unassuming but effective way in getting east-west initiatives moving.

\section{Restructuring}

Discussion of the restructuring document (page 75), which had been modified following comments to an earlier consultative version circulated in December, was the main item on the agenda. The President emphasised the importance of more feedback from delegates which did not focus on "fine details". Responses so far had been positive, some with caveats. The question of the IOM's and the proposed supporting members was still unclear, especially because the great foresight of having IOM's had been rewarded by recent events. One also had to establish with the national societies which of their members would be interested in supporting EPS activities. Much work remained to firm-up on priorities, but in general terms, Divisions operating from a ten-times larger base provide great scope. Financial implications were "difficult but not desperate" so one "could approach restructuring with optimism", mindful that "one must look at the figures carefully".

The President recommended acceptance in principle with gradual implementation to avoid a step function. He then sought opinions on the restructuring proposals, the priorities and the schedule. Most were optimistic although strong reservations on some important details remain. The main points raised in discussion will be summariwill be reported in detail in the minutes of Council and incorporated into future veroffice and O.G. Folbert and D. Horn had sed in next month's Europhysics News, and

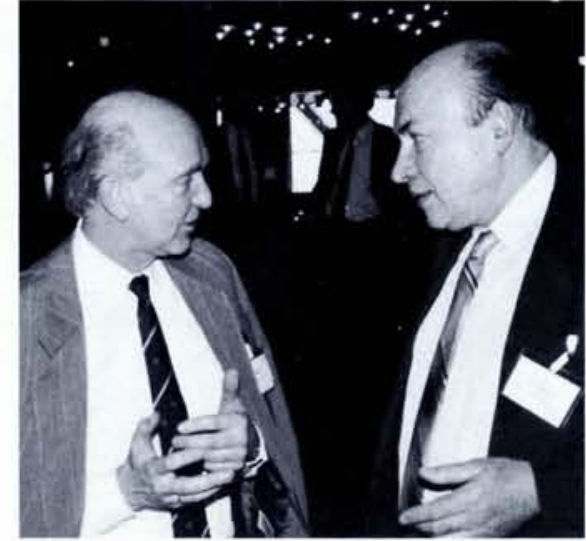

N. Kroo, EPS Vice-President, and J. Kikas, Chairman, Estonian Physical Society (on the right).

sions of the restructuring document. Council warmly endorsed the spirit of restructuring proposals, and requested that the document's best case/worst case estimates of the implied change in the Society's income be narrowed down as part of an implementation scheme, to be presented at the next Council.

\section{East-West Task Force}

O.G. Folberth, the retiring Chairman of the EWTF, hands over to A. Landesman who was recently appointed to the Task Force. Council approved the Executive Committee's proposal to recognise the significance of the Task Force by making it an Action Committee called the East-West Coordination Committee (EWCC). As there is no "'big money" available Professor Folberth stressed the importance of partnerships between groups in the east and west. Personal initiatives are vital to establish them. But the east must help by coming up with specific proposals. Judging by the record, progress is encouraging. For instance, the German Physical Society had agreed to sponsor a school in Romania following contacts during the Task Force's activities (A. Calboreanu, Secretary, Romanian Physical Society).

From Switzerland: seated in the front row (from the left) - J. Muller (Swiss Physical Society), E. Heer and W. Merz. From Germany: standing - W. Heinicke (Executive-Secretary, German Physical Society); seated in the second row (from the left) - G. Röpke (GPS), O.G. Folberth (GPS) and W. Buckel.

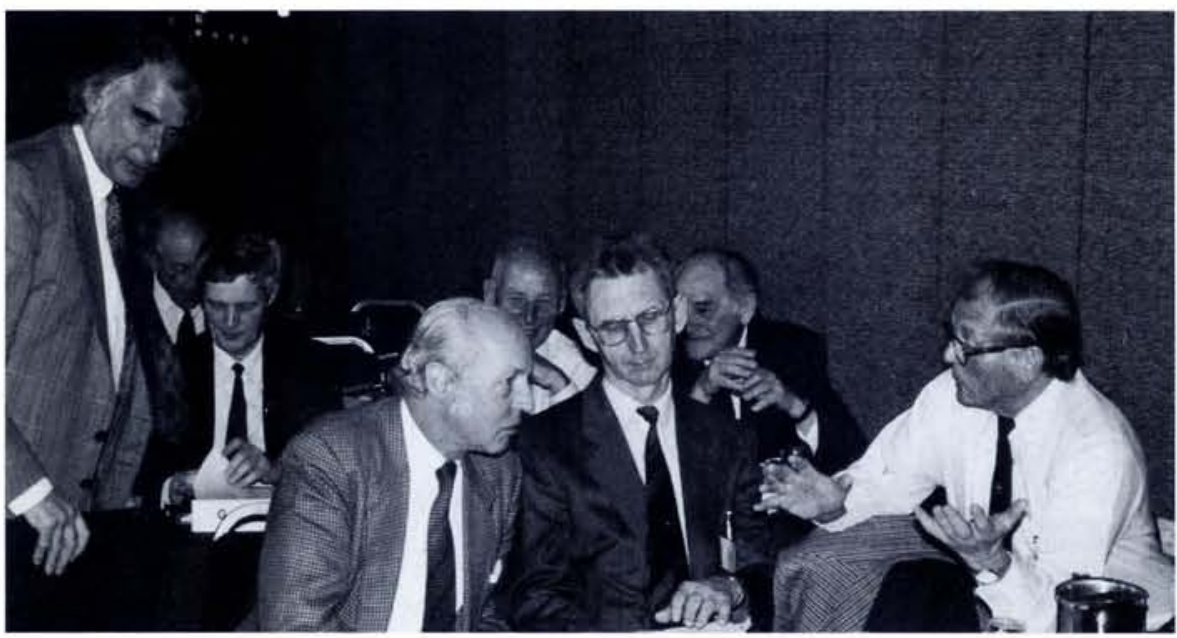

While future emphasis should be to assist individual physicists "at the bench", Professor Folberth was very pleased to hear that partnerships between physical societies were developing. In particular:

- R.A. Ricci announced that the Italian Physical Society would establish agreements to help societies in the Balkans.

- G. Tibell (President, Swedish Physical Society) announced that his society would shortly vote on a proposal to help the Estonian society by splitting membership fees between the Finnish, Swedish and Estonian societies.

- The Swiss Physical Society will shortly vote on a proposal to set up a fund administered by the EPS to help cover the fees of national societies in C\&EE.

- The German Physical Society discussed at its 56th Physikertagung in Berlin a few days after Council ways in which it could give additional help. A coordinated plan will be announced later this year.

E.W.A. Lingeman, the Secretary of the Task Force, in filling in the details, described the sorts of initiatives that could be expected from developing a collaboration with the American Physical Society. They included possible Europhysics Study Conferences on the management of science similar to the one held in Dagstuhl last year, but tailored for the Baltic States and eventually for the former Soviet Union. These would be necessary first steps in evaluations of the needs and where help should be targeted. J. Depireux would be asked to join the Task Force to develop initiatives in the area of education in spite of the absence of "scientific Thatcherism" in the C\&EE (F. Mezei, Chairman, Publications Committee) and a generally high standard of education. He might take note of recent proposals to the Romanian government by the country's physical society for developing physics education, notably curricula and teaching in the polytechnics (A. Calboreanu). Completing the Directory of Physics Institutes remained a priority.

Further help for C\&EE was announced by A.M. Hoogenboom (Chairman, Europhysics

From Czechoslovakia: on the left, L. Eckertovà (Union of Czechoslovak Mathematicians and Physicists) and J. Fischer (IOM Delegate).

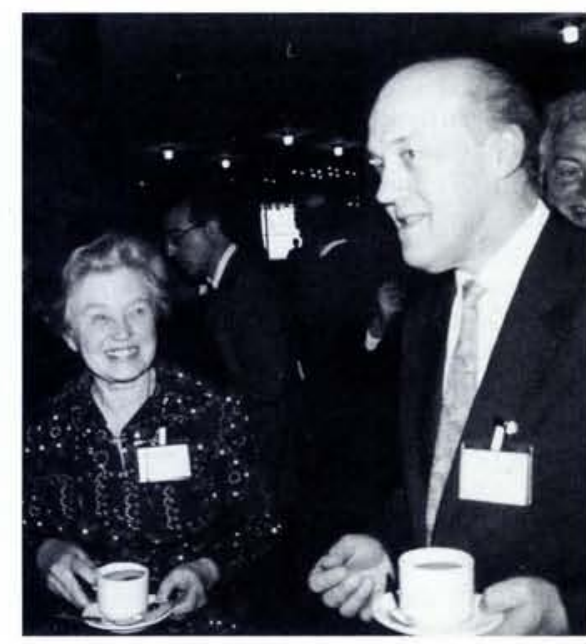




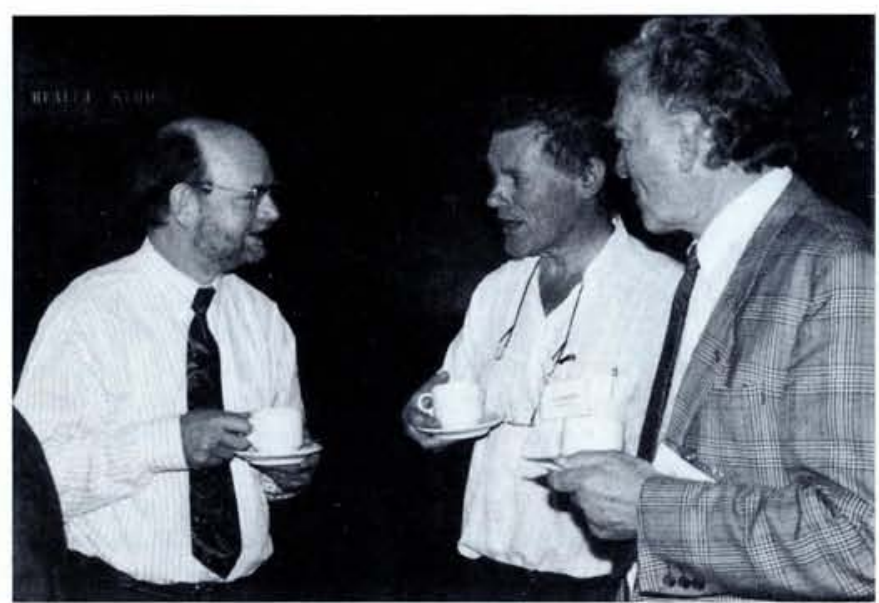

From the left, F.W. Sluijter (Plasma Physics), R. Dekeyser (Belgian Physical Society) and C. van der Leun (The Netherlands' Physical Society).

Letters Management Board) whereby Letters planned to build up an EPS fund to subsidise subscriptions in the region.

\section{Divisions}

Commenting on reports by Chairmen of the Divisions (which will be summarised in next month's Europhysics News), the President was very encouraged by the level of activity. He asked for reports on the recently established links with the Japanese and American societies by the end of the year. The main item dealt with by Council was approval of a "letter of interest" to form a joint Astrophysics Division with the European Astronomical Society (EAS). The President explained that $P$. Lena had agreed to become the Division's Chairman and that the aim was to cater for a community whose members lean towards either physics or astronomy.

W. Mattig (Chairman, Solar Physics) said that the EAS will ratify the agreement with the EPS at its first annual meeting in June. Details of the joint Division had not yet been discussed with the EAS, but the plan was to have Sections belonging to either EPS or EAS.

\section{EPS-9 General Conference}

R.A. Ricci (Conference Chairman, EPS-9) and E. Brézin (Programme Chairman) announced that plans for the EPS-9 in 1993 in Florence were now well underway. The meeting, to be held in the Palazzo dei Congressi, will comprise the usual blend of plenary lectures (12 this time) and parallel sessions (24). The number and variety of proposed topics will undoubtedly ensure another stimulating programme. W. Buckel has been nominated as the Cecil Powell Memorial Lecturer and V. Tognetti chairs the Local Organizing Committee.

A ceremony to celebrate the 25th anniversary of EPS will be held in the Palazzo Vecchio, site of the first EPS general conference. G. Bernardini - a founding father of EPS - has agreed to attend. Unfortunately, there is only room for 500 invited guests and dignitaries. However, space in an adjoining room can cater for the media and a video audience. The organizers, building on

\section{Student Mobility}

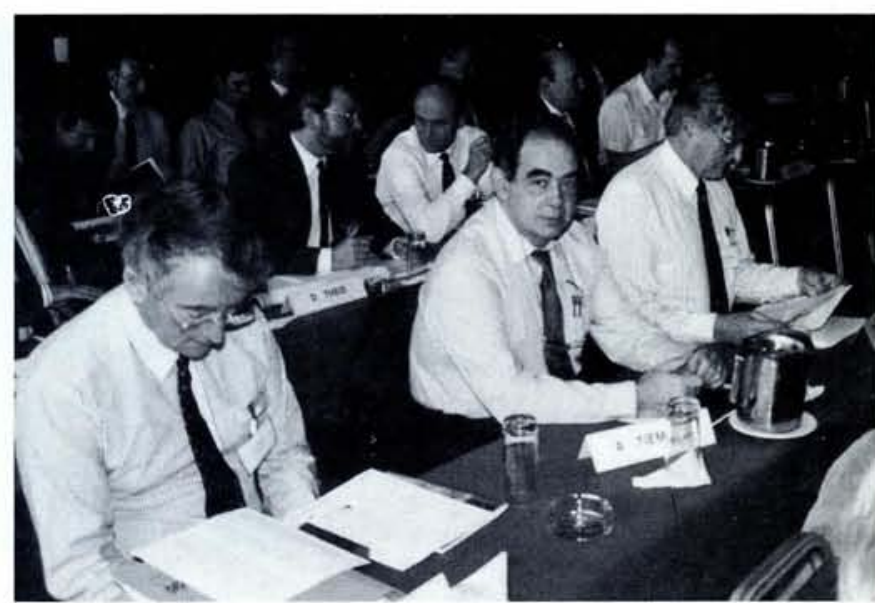

From the left, A. Jones (Executive-Secretary, Institute of Physics), A. Tiemblo (Spanish Royal Physical Society) and W. Kündig (Swiss Physical Society).

the experience of EPS-8 in Amsterdam, are very conscious of the need to provide good quality but low-cost accommodation to young people, an adequate coverage of applied topics, and talks pitched at a suitable level. N. Kroo, based on feedback from Hungarian participants, urged the same level as EPS-8; others felt a reduction was needed.

P.G. Boswell reported that North-Holland had agreed to produce a 100-120 page, journal-sized anniversary booklet on the EPS's behalf for distribution to EPS-9 participants and perhaps others. This monograph on the history of EPS will be coordinated and edited by members of a special task force.

E. Heer (Chairman, Student Mobility Working Group) reported that 37\% (165) of the 418 physics institutes responsible for physics teaching that were felt to qualify with the requirements of the proposed mobility programme had replied positively to a questionnaire. Of the 165 , some $81 \%$ agreed to a draft convention without modification and $90 \%$ said they would limit the number of students accepted. The main problems are unbalanced flows, the need to pay fees (mainly in the UK) and a poor response from certain countries. Council agreed to go ahead with the scheme and approved a third draft of the convention.

In working towards starting the scheme in October 1993, the institutions which replied positively will shortly be asked to ratify the convention. Meanwhile, efforts to obtain support from European Community

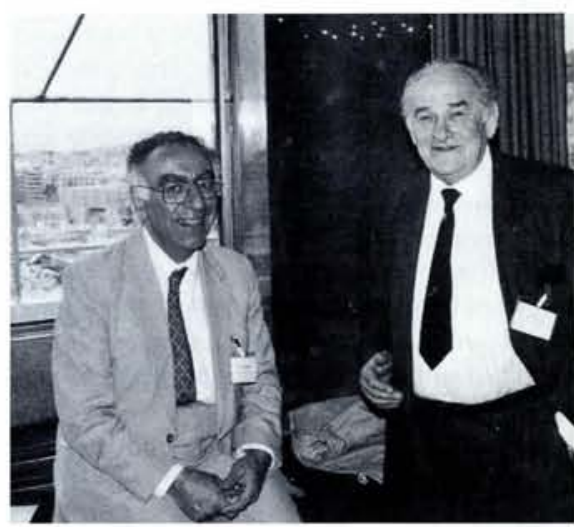

R. Balian (on the left) who takes over from W. Buckel (on the right) as Editor-in-Chief of Europhysics Letters.

(EC) programmes are continuing in spite of not knowing in advance the funds needed. H.G. James of Manchester University, UK, is arranging to set up a computer database.

\section{Professional Qualifications}

Council agreed to proposals by D. Jefferies (Chairman, Working Group on Professional Qualifications) that the notion of a European professional title in physics be accepted, and that the Group should put before the next Council detailed recommendations on implementation. He described how other scientific communities (biologists, chemists and geologists) were at various stages in setting up European registers based on formation, often drawing on the experience of engineers who pioneered
The 1991 EPS Executive Committee: from the left, W. Merz, E. Jakeman, O.G. Folberth, Ph. Choquard, H. Ryde, N. Kroo, M. Jacob, R.A. Ricci, G. Thomas, and I. Slaus.

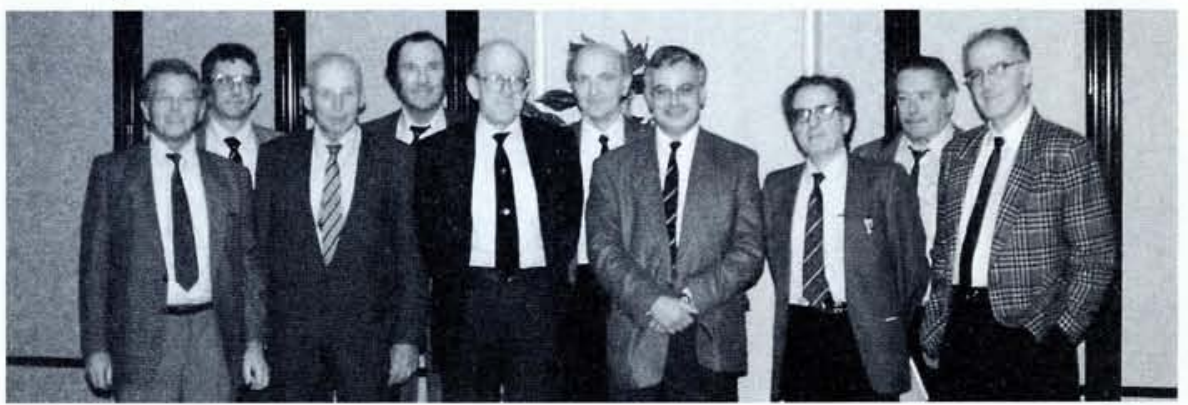


this difficult task. A few countries had already established, or were creating, national titles in science but the European Community's intentions were unclear, especially since it now appeared possible to obtain an "EC endorsement".

\section{Publications}

E. Buckel handed over the position of Editor-in-Chief of Europhysics Letters to R. Balian for whom the "privilege had given me duties". Professor Balian is the proud co-author of the very first paper to have appeared in the journal. Professor Buckel explained that Letters had to cope with an increase in the number of submissions by increasing the number of annual volumes.

P.G. Boswell speaking on behalf of $F$. James (Chairman, Europhysics News Editorial Board) described the progress that had been made in publishing more Directory-type information and more news - both technical and otherwise. The number of general review articles was significantly smaller in 1991 than in 1990, this being compensated for by "targeted" collections of shorter features. Lower costs arising from the introduction of electronic production techniques had unfortunately been swamped by increases in mailing charges. It was planned to modernise distribution to the IOM's by introducing more cost-effective plastic wrappers.

Council closed a constructive, busy and largely optimistic meeting with a short tribute by $H$. Ryde to the President's enthusiasm and drive.

\section{Decisions of EPS Council}

At its meeting on 27-28 March 1992, the Council made the follow decisions:

- To admit the Physical Societies of Albania, Croatia, Estonia, and Lithuania.

- To accept 397 new Individual Ordinary Members and 8 new Associate Members.

- To accept the proposed budget for 1992 that seeks a surplus of almost $60 \mathrm{kSFR}$.

- To endorse the proposals for a restructured society, as outlined in the discussion document $A$ New EPS Structure, and to have detailed proposals for implementation tabled at the next Council Meeting.

- To approve the formation of an Astrophysics Division jointly with the European Astronomical Society.

- To accept the appointment of A. Landesman as the Chairman of the East-West Task Force which now becomes the East-West Coordination Committee (EWCC).

- To endorse the initiatives of the East-West Task Force (now the EWCC) and its plan to develop further actions in cooperation with the American Physical Society.

- To endorse the proposed arrangements for the 1993 General Conference and for the 25th Anniversary of EPS.

- To approve the launching of the European Mobility Scheme for Physics Students.

- To accept the notion of a European professional title in physics and to seek proposals for its implementation at the next Council Meeting.

- To consider nominations for Honourary Membership at the next Council Meeting.

- To elect as the Executive Committee for the year 1992/3 the following:

President: M. Jacob, Geneva

Vice-President: N. Kroo, Budapest

Secretary: A. Taroni, Brescia

Vice-Secretary: C. van der Leun, Utrecht

Treasurer: $\quad \mathrm{Ph}$. Choquard, Lausanne

Vice-Treasurer: E. Jakeman, Malvern

- To hold future Council Meetings as follows:

1993: 26-27 March, Nice

1994: 25-26 March, Cracow or Warsaw

1995: 31 March-1 April, Berlin or Bad Honnef
Members: A.F. Andreev, Moscow

C.M. Ferreira, Lisbon

E. Osnes, Oslo

E. Schopper, Geneva

I. Slaus, Zagreb

1996: 29-30 March, Portugal 1997: 21-22 March, Spain

\section{- Dutch React to Shortened Degree}

Degree courses for physicists in The Netherlands were reduced in length in 1982 to four years in both the universities (doctorandus, drs.) and technical universities (ingenieur, ir.). The average graduation time has meanwhile gone from 6.9 years to 4.9 years in 1991. A report of The Netherlands Physical Society by G. Maurice, published last month, of a survey finalised in October 1991 gauges the effects of the change for the first time. Considering students starting "old style" (OS) courses in 1979-84 and "new style" (NS) courses in 1985-90, the percentage of the numbers of drs. and ir.

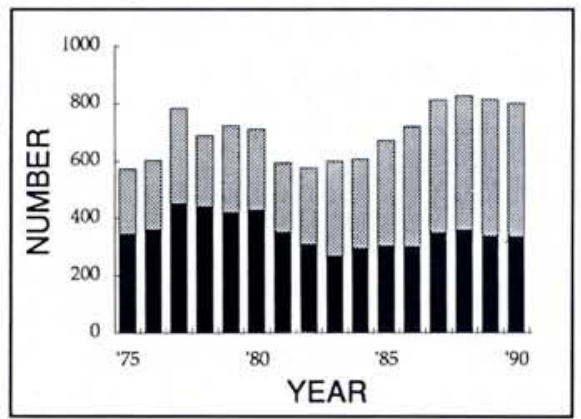

The numbers of first-year student in physics (solid black) and technical physics (shaded) in The Netherlands [FOM Report 68747 (1991)]. moving on to further studies (mostly Ph.D. level) increased from $64 \%$ for OS to $77 \%$ for NS. Of students moving to full-time employment, the percentage of drs. moving to major industrial companies nearly halved (35\% to $19 \%$ ) as compared with ir. where the decrease was much less ( 55 to $48 \%$ ). Smaller industry increased its share of physicists in first-time employment by roughly the same amount for both drs. ( 37 to $44 \%$ ) and ir. (26 to $37 \%$ ). Drs. moving to (semi)government organisations increased from 27 to $36 \%$ while the percentage for ir. actually decreased from 19 to $15 \%$.

E.W.A. Lingeman, the secretary of the Commission which made the survey, thinks the trends reflect the believe among graduates that industry seeks a longer training. It will therefore be interesting to see if new style Ph.D.'s presently starting to enter employment favour industry. For old style Ph.D.'s covered by the survey, the main part $(44 \%$ ) moved to (semi)government, $35 \%$ to major industry, and $19 \%$ to small companies. Moreover, will equivalent reactions materialise elsewhere? Germany is thinking about reducing, and the UK extending, firstdegree courses.

The 1982 changes also led to a surge in the numbers (both total and first year) of physics students enrolled in Holland's four technical universities [FOM Report 68747

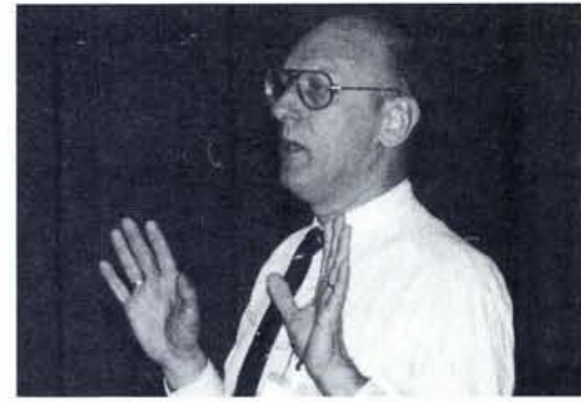

E.W.A. Lingeman, Chairman of the EPS Physics and Society Committee and Secretary of the EPS East-West Coordination Committee, speaking at Council in Athens.

(May 1991)]. The number of first years at TU Delft, the largest, in fact now appears to exceed the number at the largest university physics department for the first time (this is currently being checked). The universities have responded by opening technical physics departments of their own.

\section{FOM towards 2000}

In outlining the rôle it sees for itself in the coming years, the Foundation for Fundamental Research on Matter (FOM), Holland's largest government-supported organisation in physics, recently published a strategic plan (FOM Towards 2000) as an 